\title{
Erratum to: Tailored behavioral medicine intervention for enhanced physical activity and healthy eating in patients with obstructive sleep apnea syndrome and overweight
}

Helena Igelström • Margareta Emtner • Eva Lindberg • Pernilla Åsenlöf

Published online: 18 February 2015

(C) Springer-Verlag Berlin Heidelberg 2015

Erratum to: Sleep Breath (2014) 18:655-668

DOI: $10.1007 / \mathbf{s} 11325-013-0929-x$

Unfortunately, when this paper was originally published, the first name and surname of each author were swapped. The correct order of the author names is presented below.

\section{First name Surname}

Helena Igelström

Margareta Emtner

Eva Lindberg

Pernilla Åsenlöf

The online version of the original article can be found at http://dx.doi.org/ 10.1007/s11325-013-0929-x.

H. Igelström $(\bowtie) \cdot$ M. Emtner $\cdot$ P. Åsenlöf

Department of Neuroscience, Physiotherapy, Uppsala University,

Box 593, BMC, Uppsala SE-751 24, Sweden

e-mail: helena.igelstrom@neuro.uu.se

M. Emtner

e-mail: margareta.emtner@neuro.uu.se

P. Åsenlöf

e-mail: pernilla.asenlof@neuro.uu.se

M. Emtner $\cdot$ E. Lindberg

Department of Medical Sciences, Respiratory Medicine and

Allergology, Uppsala University, Uppsala, Sweden

E. Lindberg

e-mail: eva.lindberg@medsci.uu.se 